\title{
A New Species of Free-living Nematode of Daptonema (Monohysterida: Xyalidae) from the Yellow Sea, China
}

\author{
Yong Huang \\ College of Life Sciences, Liaocheng University \\ 1 Hunan Road, Liaocheng, 252059, China \\ E-mail: huangyong@1cu.edu.cn
}

Kuidong $\mathrm{Xu}$

Institute of Oceanology, Chinese Academy of Sciences

3 Nanhai Road, Qingdao, 266003, China

E-mail: kxu@qdio.ac.cn

Received: August 18, 2012 Accepted: September 14, 2012 Published: January 1, 2013

doi:10.5296/ast.v1i1.2443 URL: http://dx.doi.org/10.5296/ast.v1i1.2443

\begin{abstract}
A new species of free-living marine nematode, Daptonema macrostoma sp. nov. from the Yellow Sea, China is described. The new species is characterized by uniquely large buccal cavity, four cephalic setae, amphid circular, S-shaped spicules with a hook at its distal end, gubernaculum invisible and tail conical-cylindrical.
\end{abstract}

Keywords: Nematode taxonomy, Daptonema macrostoma sp. nov., Yellow Sea of China 


\section{Introduction}

In order to study the biodiversity of free-living marine nematodes in the Yellow Sea, China, sediment samples were collected in many sites from the intertidal to the sublittoral region along the Yellow Sea in the past few years. More than 240 species have been identified from these habitats up to now (Huang et al., 2006; Huang \& Cheng, 2012). The present paper describes one new species from this region which belong to the genus Daptonema Cobb, 1920 .

The genus Daptonema was established by Cobb in 1920 with the type species $D$. fissidens Cobb, 1920. This genus includes more than 120 species and presents particular difficulty for identification. Wieser (1956) considered Daptonema as one of five subgenera of Theristus. This subdivision was refuted again by Lorenzen (1977) in a review of the Xyalidae. Daptonema species are separated from those of Theristus only by the shape of the tail: conico-cylindrical with terminal setae in the former, conical without terminal setae in the latter. Within Daptonema, species are distinguished by rather few characters: mainly the relative length of the setae, size and position of the amphids, size and structure of the copulatory apparatus and the shape and length of the tail (Warwick et al., 1998).

So far, more than 120 species of Daptonema have been recorded (Gerlach \& Riemann, 1973; Tchesunov \& Miljutin, 2006; Huang \& Zhang, 2010; Electronic databases http://nemys.ugent.be and http://insects.tamu.edu/research/collection/hallan/Nematoda). The new species $D$. macrostoma sp. nov. differs from the other species in this genus by its uniquely large buccal cavity, four short cephalic setae and S-shaped spicules with a hook at its distal end.

\section{Materials and Methods}

In July 2008, undisturbed sediments were obtained from a grid of 33 sampling stations between $32^{\circ} \mathrm{N}$ and $38.83^{\circ} \mathrm{N}, 120.34^{\circ} \mathrm{E}$ and $124.167^{\circ} \mathrm{E}$ during the Open Research Cruise by $\mathrm{R} / \mathrm{V}$ KE XUE SAN HAO in the Yellow Sea, China. Undisturbed sediment samples were taken using a $0.1 \mathrm{~m}^{2}$ improved Gray-O'Hara box, and a $8 \mathrm{~cm}$ depth of meiofauna samples were obtained using a sawn-off syringe with a $2.6 \mathrm{~cm}$ inner diameter. Samples were fixed with $5 \%$ formalin in filtered seawater. In the laboratory, samples were stained with $0.1 \%$ Bengal rose for about 24 hours. All the samples were washed to remove the formalin and sieved over two mesh sizes $(500 \mu \mathrm{m}$ and $42 \mu \mathrm{m})$ in order to separate the macrofauna (500 $\mu \mathrm{m})$ from the meiofauna $(42 \mu \mathrm{m})$. Heavier sediment particles were removed using centrifugation in Ludox- ${ }^{\mathrm{TM}}$ with a specific gravity adjusted to 1.15 (Jonge \& Bouwman, 1977). Each sample was washed into a lined Petri dish and the meiofauna was sorted under a stereoscopic microscope up to higher taxonomic levels. Nematodes were transferred into a 9:1 (V : V) solution of 50\% ethanol : glycerol in block cavity to slowly evaporate ethanol and then mounted in glycerol on permanent slides. The descriptions were made from glycerin mounts using interference contrast microscopy (Nikon, 80i). Drawings were made with a camera lucida. Type specimens have been deposited in the type collections of the Museum of Qingdao Institute of Oceanology, Chinese Academy of Sciences. 
Measurements are in $\mu \mathrm{m}$. Abbreviations are as follows:

de Man a: body length / max. body diameter; a.b.d.: anal body diameter; de Man b: body length / oesophagus length; de Man c: body length / tail length; c.b.d.: corresponding body diameter; h.d.: head diameter; Spic: spicule length along the arc; V: corresponding body diameter of vulva; $\mathrm{V} \%$ : position of vulva from anterior end expressed as a percentage of total body length.

Order Monhysterida Filipjev, 1929

Family Xyalidae Chitwood, 1951

Genus Daptonema Cobb, 1920.

Daptonema macrostoma sp. nov.

\subsection{Type Material}

Four males and one female collected from Station 3400-0 and 3400-1.

Holotype: 1 1on the slide 3400002; Allotype: 1 on the slide 3400002; Paratypes: three males on the slides 3400002 and 3400121 .

\subsection{Type Locality and Habitat}

Subtidal muddy sediment in the Yellow Sea. Station 3400-0: $34^{\circ} \mathrm{N}, 120^{\circ} 36^{\prime}$ E, water depth $40.5 \mathrm{~m}$, water temperature at the sediment-water interface $11.6^{\circ} \mathrm{C}$, salinity 33 , silt $86 \%$, clay $13 \%$, sand $0.7 \%$, organic matter $0.4 \%$. Station $3400-1: 34^{\circ} \mathrm{N}, 120^{\circ} 48^{\prime} \mathrm{E}$, water depth $48 \mathrm{~m}$, water temperature at the sediment-water interface $11.2^{\circ} \mathrm{C}$, salinity 33.2 , silt $87 \%$, clay $12 \%$, sand $0.7 \%$, organic matter $0.42 \%$.

\subsection{Etymology}

This species name refers to its very large buccal cavity. 
A

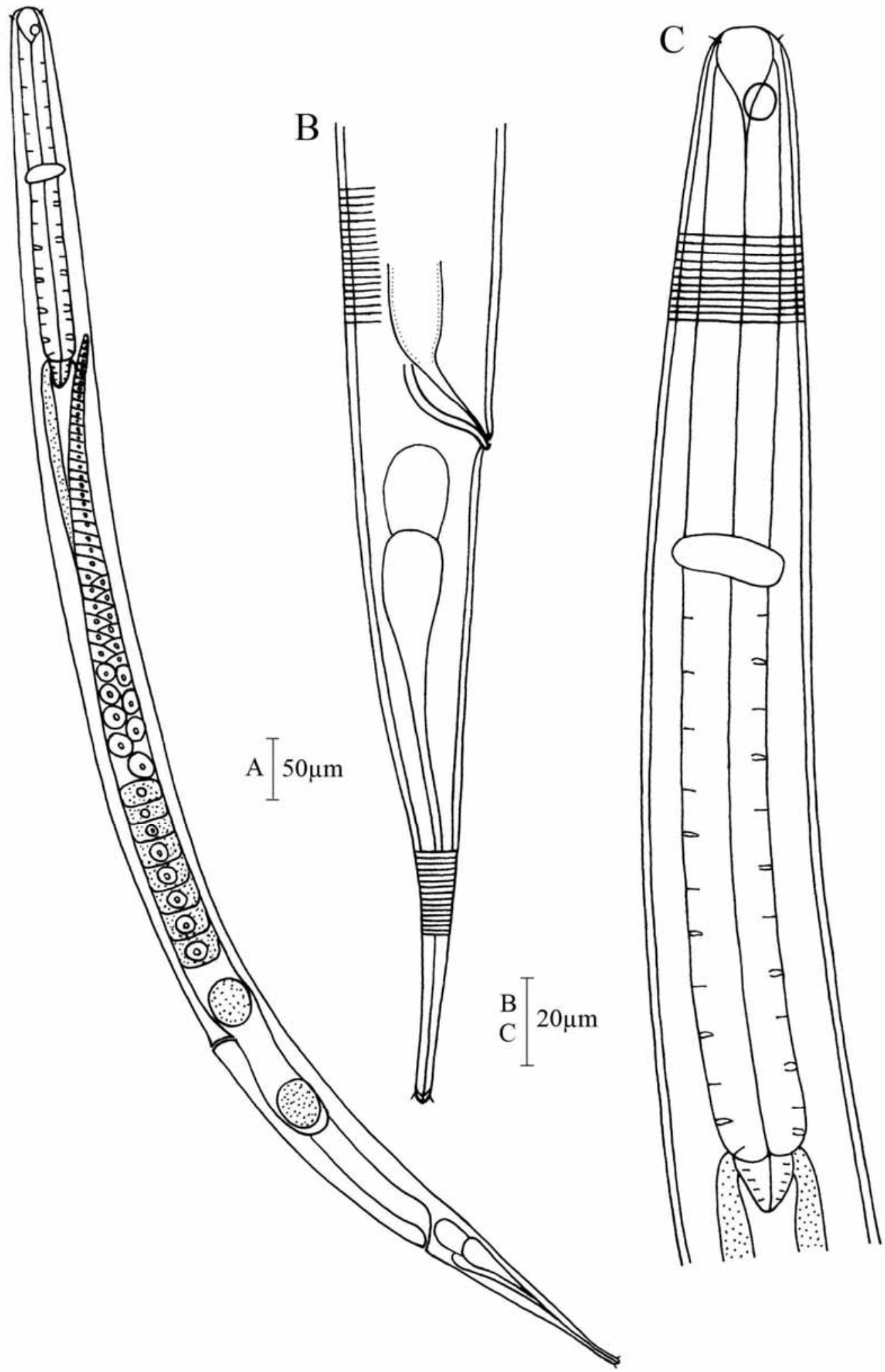

Figure 1. Daptonema macrostoma sp. nov. (A) lateral view of female body, showing reproductive system and vulva; (B) lateral view of male tail region, showing spicule and caudal glands; (C) lateral view of male anterior end, showing buccal cavity, cephalic setae, amphids, pharynx and cardia 

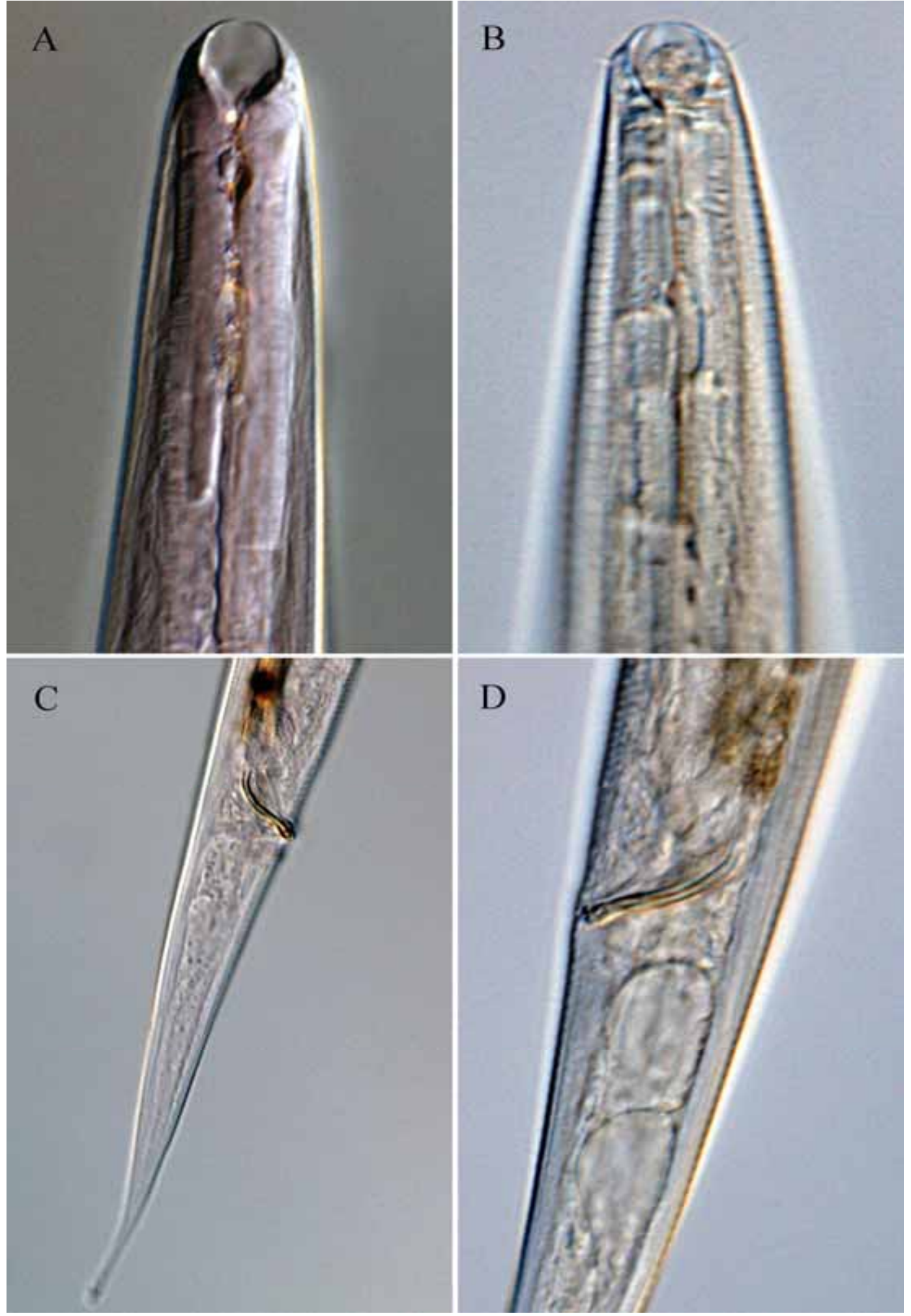

Figure 2. Daptonema macrostoma sp. nov. (A) lateral view of female anterior end, showing buccal cavity; (B) lateral view of male anterior end, showing buccal cavity and cephalic setae; (C) lateral view of male posterior end, showing spicule and tail; (D) lateral view of male cloaca region, showing spicule and caudal glands 


\section{Measurements}

Table 1. Individual measurements (and average) of Daptonema macrostoma sp. nov. $(\mu \mathrm{m})$

\begin{tabular}{|c|c|c|c|c|c|c|}
\hline Characters & $\partial^{\lambda} 1$ & 32 & 3 & $\widehat{\partial} 4$ & q1 & Average \\
\hline Total body length & 1150 & 1151 & 1183 & 1078 & 1281 & 1169 \\
\hline Maximum body diameter & 49 & 51 & 53 & 42 & 59 & 51 \\
\hline Head diameter & 17 & 19 & 18 & 16 & 21 & 18 \\
\hline Width of mouth & 15 & 14 & 14 & 13 & 16 & 14.4 \\
\hline Length of cephalic setae & 3 & 3 & 3 & 3 & 4 & 3.2 \\
\hline Nerve ring from the anterior end & 125 & 116 & 125 & 110 & 135 & 122 \\
\hline Nerve ring c.b.d. & 39 & 40 & 44 & 35 & 49 & 41 \\
\hline Pharynx length & 276 & 270 & 273 & 260 & 305 & 277 \\
\hline Pharynx c.b.d. & 46 & 48 & 49 & 39 & 54 & 47 \\
\hline Spicule length as arc & 28 & 30 & 30 & 30 & - & 29.5 \\
\hline a.b.d. & 31 & 34 & 32 & 30 & 37 & 32.8 \\
\hline Tail length & 164 & 163 & 176 & 160 & 176 & 167.8 \\
\hline Tail length / a.b.d. & 5.3 & 4.8 & 5.5 & 5.3 & 4.8 & 5.1 \\
\hline Vulva from anterior end & - & - & - & - & 877 & 877 \\
\hline Vulva c.d. & - & - & - & - & 59 & 59 \\
\hline $\mathrm{V} \%$ & - & - & - & - & 69 & 69 \\
\hline $\mathrm{a}$ & 23.5 & 22.6 & 22.3 & 25.7 & 21.7 & 23.2 \\
\hline $\mathrm{b}$ & 4.2 & 4.3 & 4.3 & 4.1 & 4.2 & 4.2 \\
\hline $\mathrm{c}$ & 7.0 & 7.1 & 6.7 & 6.7 & 7.3 & 7.0 \\
\hline
\end{tabular}

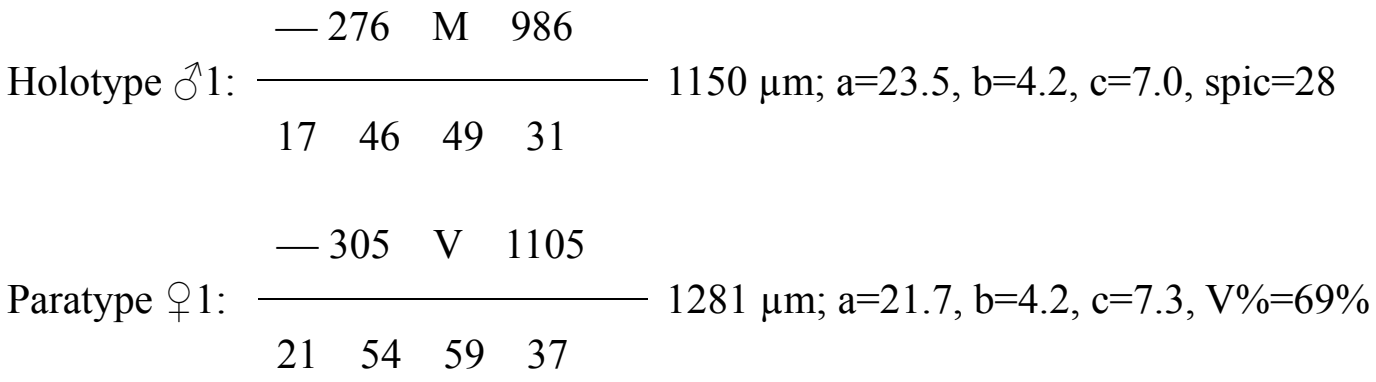

\section{Description}

Males. Body slender, gradually tapering towards both extremities. Cuticle with coarse annulations, beginning at base of buccal cavity and ending at tail tip. Labial sensilla not visible. Four short cephalic setae in one circle, $3 \mu \mathrm{m}$ long. Short somatic setae scattered over body. Buccal cavity very spacious, $15 \mu \mathrm{m}$ wide, square-rounded, consists of hemispherical cheilostom and conical pharyngostom. Amphids circular, $8 \mu \mathrm{m}$ in diameter $(36 \%$ of corresponding body diameter wide), situated at a distance of $15 \mu \mathrm{m}$ from the anterior end. Excretory pore not obvious. Pharynx cylindrical. Cardia long cordiform. Nerve ring at about $45 \%$ of pharyngeal length. Tail conico-cylindrical, $164 \mu \mathrm{m}$ long (5.3 a.b.d.), tapering with 
distal third cylindrical and three terminal setae. Three caudal glands with common opening.

Spicules S-shaped, $28 \mu \mathrm{m}$ long as arc, slender and tapered with a hook distally. Gubernaculum invisible. No precloacal supplement.

Females. Females have most features in common with males, but are slightly larger. A single anterior outstretched ovary, about $570 \mu \mathrm{m}$ long. Vulva at $69 \%$ of body length from the anterior end.

\section{Differential Diagnosis}

Daptonema macrostoma sp. nov. is characterized by great buccal cavity, four cephalic setae, $\mathrm{S}$-shaped spicules with a hook at the distal end and gubernaculum invisible. This new species is close to D. deconincki Sharma, 1985 in the size and structure of the body. Nevertheless, the spicules of the latter species have bifid tips, $49 \mu \mathrm{m}$ long, the gubernaculum surrounds the distal half of the spicules and with a dorsal apophysis. This new species also resembles $D$. setosum (Bütschli, 1874) Filipjev, 1930, which has a very big and broad gubernaculum and spicules L-shaped, distally bifurcate.

\section{Acknowledgements}

This work was supported by the National Science Foundation of China (No.41176107), the Knowledge Innovation Program of the Chinese Academy of Sciences (No. KZCX2-YW-417) to $\mathrm{K} . \mathrm{Xu}$, and the Open Research Cruise offshore China by R/V KE XUE SAN HAO, Institute of Oceanology, Chinese Academy of Sciences (IOCAS) in July 2008. The authors are very grateful to Mr. Renhai Dai and Ms. Zhaocui Meng, IOCAS, for their help for sampling.

\section{References}

Cobb, N. A. (1920). One hundred new nemas (Type species of 100 new genera). Waverly press, Baltimore.

Gerlach, S. A., \& Riemann, F. (1973). The bremerhaven checklist of aquatic nematodes (Part 2). Veröff. Inst. Meeresforsch. Bremerch.

Higgins, R. P., \& Thiel, H. (1988). Introduction to the study of meiofauna. Washington DC: Smithsonian Institution Press.

Huang, Y., \& Cheng, B. (2012). Three new free-living marine nematode species of the genus Micoletzkyia from China Sea. Journal of the Marine Biological Association UK, 92(5), 941-945. http://dx.doi.org/10.1017/S0025315411000476

Huang, Y., \& Zhang, Z. N. (2010). Two new species of Xyalidae (Nematoda) from the Yellow Sea, China. Journal of the Marine Biological Association UK, 90, 391-397. http://dx.doi.org/10.1017/S0025315409000794

Huang, Y., Zhang, Z. N., \& Liu, X. S. (2006). Studies on the species composition and biodiversity of Free-living marine nematode in the Southern Yellow Sea, China. Acta Oceanologica Sinica, 25(2), 87-98. 


\section{Macrothink}

Aquatic Science and Technology

ISSN 2168-9148 2013, Vol. 1, No. 1

Jonge, V. N., \& Bouwman, L. A. (1977). A simple density separation technique for quantitative isolation of meiobenthos using the colloidal silica Ludox- ${ }^{\mathrm{TM}}$. Marine Biology, 42, 143-148. http://dx.doi.org/10.1007/BF00391564

Lorenzen, S. (1977). Revision der Xyalidae (freilebende Nematoden) auf der Grundlage einer kritischen Analyse von 56 Arten aus Nord- und Ostsee. Veröffentlichungen Instituts für Meeresforschung in Bremerhaven, 16, 197-261.

Tchesunov, A. V., \& Miljutin, D. M. (2006). Three new free-living nematode species (Monhysterida) from the Arctic abyss, with revision of the genus leutherolaimus Filipjev, 1922 (Linhomoeidae). Russian Journal of Nematology, 14(1), 57-75.

Warwick, R. M., Platt, H. M., \& Somerfied, P. J. (1998). Free-living marine nematodes part III: Monhysterids, (Synopses of the British Fauna No. 53), Field Studies council Shrewsbury.

Wieser, W. (1956). Free-living marine nematodes III. Axonolaimoidea and Monhysteroidea. Lunds Universitets Arsskrift (N. F. 2), 52, 1-115.

\section{Copyright Disclaimer}

Copyright reserved by the author(s).

This article is an open-access article distributed under the terms and conditions of the Creative Commons Attribution license (http://creativecommons.org/licenses/by/3.0/). 